\title{
Threshold effect of foreign direct investment on environmental degradation
}

\author{
Shu-Chen Chang ${ }^{1}$
}

Received: 14 March 2013 / Accepted: 3 November 2015 /Published online: 12 November 2015

\# ISEG 2015

\begin{abstract}
The aim of this paper is to investigate the threshold effect of foreign direct investment (FDI) on environmental degradation. In empirical analysis, FDI and environmental degradation are jointly determined under the given threshold variable and other exogenous variables. Using carbon dioxide $\left(\mathrm{CO}_{2}\right)$ emissions per capita as a proxy for environmental degradation, the results show that increasing FDI worsens $\mathrm{CO}_{2}$ emissions after a threshold level of corruption has been reached. Our results demonstrate that increasing FDI will increase $\mathrm{CO}_{2}$ emissions when the degree of corruptibility is relatively high. The study suggests that further FDI and improved environmental quality are competing rather than compatible objectives in highcorruption countries and are compatible rather than competing objectives in lowcorruption countries. Higher trade liberalization in low-corruption countries could contribute to negative environmental consequences because of the increased output or economic activity which results from increased trade. The robustness estimation confirms the evidence that pollution and economic development increase together up to a certain income level, after which the trend reverses.
\end{abstract}

Keywords $\mathrm{CO}_{2}$ emissions $\cdot$ Environmental degradation $\cdot$ Foreign direct investment . Threshold models

JEL Classification $\mathrm{O} 1 \cdot \mathrm{Q} 4$

Shu-Chen Chang

shu-chen@nfu.edu.tw

${ }^{1}$ Department of Business Administration, National Formosa University, Yunlin, Taiwan 